\title{
A Clinical Study of a Short Stroke Reciprocating Action Electric Toothbrush*
}

\author{
BY BERNARD L. RAINEY,** D.D.s., M.s. AND M. M. ASH, JR., *** D.D.s., M.s.
}

$\mathrm{T}$

HERE are approximately forty reports in the literature on the effectiveness of the electric toothbrush. These reports show that a wide variety of patients, ${ }^{2,9,14,17,20,23}$ methods, ${ }^{3,4,6,8,10,15,23,25}$ and criteria ${ }^{3,5,7,11,13,16,19,24}$ for evaluating the effectiveness of electric brushes have been used. However, only one of the more objective studies ${ }^{22}$ has used multiple criteria of effectiveness and provided for standardization of the errors in scoring the criteria. From the standpoint of the periodontist who depends greatly on the role of the toothbrush for maintenance of oral hygiene, studies using periodontal maintenance subjects are more likely to be of interest than studies utilizing other types of patients.

The purpose of this study was to determine in periodontal maintenance subjects: (1) the effectiveness of the short stroke reciprocating action toothbrush in preventing the formation of dental plaque or in removing dental plaque, in preventing or reducing gingivitis, and in preventing calculus formation; and (2) its effect on the gingival crevice depth and periodontal disease index.

\section{SAMPLE AND METHODS}

Types of Patients. Subjects used in this study were adult male and female patients selected from the dental clinic of the University of Michigan. These patients were on periodontal maintenance, that is, all periodontal therapy and restorative dentistry requirements had been completed. Initially 78 patients were selected, 35 males and 43 females. Ages of subjects in this study varied from 21 years of age to 73 years of age with the mean age being 43.4 years of age. Two patients were lost during the period of this study and these were not included in any of the statistical evaluations.

Oral hygiene for these subjects ranged from poor to good. This is indicated by the range of initial scores for the various criteria used in the study. With

\footnotetext{
"The opinions or assertions contained in this article are the private ones of the writers and are not to be construed as official or reflecting the views of the Air Force.

* Major, USAF DC, USAF Hospital Andrews, Andrews AFB, Maryland.

**:Professor of Dentistry, the University of Michigan School of Dentistry, Ann Arbor, Michigan.
}

Page 5/455 
scoring indices for plaque and gingivitis having a range from 0 to 3 , initial plaque scores for all subjects varied from 0.75 to 1.92 and from 0.33 to 1.67 for gingivitis. With a periodontal index having a range of 0 to 6 , the periodontal index score varied from 2.42 to 5.25 for all subjects.

Scoring Indices. The Ramfjord indices ${ }^{18}$ as modified by Smith and $\mathrm{Ash}^{22}$ were used to score plaque, gingivitis, calculus, and the periodontal disease index of six representative teeth. ${ }^{12,21}$ The modifications consisted primarily of scoring these criteria on the facial and lingual surfaces. The six teeth used in scoring were:

Tooth No. 3-the maxillary right first molar

Tooth No. 9-the maxillary left central incisor Tooth No. 12-the maxillary left first bicuspid

Tooth No. 19-the mandibular left first molar

Tooth No. 25-the mandibular right central incisor

Tooth No. 28-the mandibular right first bicuspid

Plaque. Plaque scores were recorded as:

Pl. 0: Absence of dental plaque.

P1. 1: Dental plaque in the interproximal or at the gingival margin covering less than one-third of the gingival half of the facial or lingual surface.

P1. 2: Dental plaque covering one-third to twothirds of the gingival half of the facial or lingual surface.

Pl. 3: Dental plaque covering two-thirds or more of the gingival half of the facial or lingual surface of the tooth.

Gingivitis. Findings for gingivitis were recorded as:

G 0: Absence of gingival inflammation and changes.

G 1: Mild to moderate inflammatory gingival changes not extending all around the facial or lingual surface.

G 2: Mild to moderately severe gingivitis extending around the entire facial or lingual surface.

G 3: Severe gingivitis characterized by marked redness, tendency to bleed and ulceration.

Calculus. Calculus scores were recorded as:

C 0: No calculus present.
C 1: Small amounts of supragingival calculus extending only slightly below the free gingival margin (not more than one millimeter) on the facial or lingual surface of the tooth.

C 2: Moderate amounts of supragingival and subgingival calculus, or subgingival calculus only, on the facial or lingual surface.

C 3: Abundance of supragingival or subgingival calculus on either surface.

Periodontal Scores. Recordings were:

P 0-3: The periodontal score is the same as the recorded gingivitis score when the gingival crevice did not extend apically to the cemento-enamel junction in any of the three measured areas on the facial and lingual surface.

P 4: If the gingival crevice in any of the three areas on the facial or lingual surface extended apically to the cemento-enamel junction, but not more than three millimeters (including three millimeters) in relation to the cemento-enamel junction.

P 5: If the gingival crevice in any of the three recorded areas of the facial or lingual surface extends apically from three to six millimeters (including six millimeters) in relation to the cemento-enamel junction.

$P$ 6: If the gingival crevice in any of the three recorded areas on one surface extends apically to the cemento-enamel junction more than six millimeters.

\section{METHODS OF SCORING}

Plaque Scores. Dental plaque which may be colorless and not visible to the eye was scored by applying Bismark Brown* disclosing solution to the facial and lingual surfaces of the teeth in the following order: No. 3, No. 9, No. 12, No. 19, No. 25 , No. 28. Prefabricated cotton applicators were used to apply the disclosing solution. The patient was then instructed to rinse his mouth two times with a cup of water. By visual examination scores were recorded on a chart with each tooth being scored in the same sequence each time the mouth was examined.

\footnotetext{
*Disclosing solution: Bismark Brown-3.0 grams Alcohol-10.0 cc. Glycerin-120.0 cc. Oil of anise- 1.0 drop
} 
Gingivitis Scores. The gingiva around each tooth was dried with compressed air. The marginal and attached gingiva were observed and scored for alterations from health in color, form, density, and bleeding tendency. ${ }^{18}$

Calculus Scores. The recording of calculus was based on its presence visually and/or by probing subgingivally with a periodontal probe.

Periodontal Scores. Instruments used in recording scores were a mouth mirror and a University of Michigan No. 0 periodontal probe marked at 3, 6, and 8 millimeters. The probe was kept in contact with the tooth surface and passed apically with a minimum amount of force until the crevice or pocket depth was reached. Measurements were recorded for the depth of the gingival sulcus and periodontal pockets in relation to the cemento-enamel junction. Measurements were rounded to the nearest millimeter with estimates at half millimeter being rounded to the lower whole number. ${ }^{12}$ Measurements were taken with the probe parallel to the long axis of the tooth on each facial and lingual surface at the mesial, mid-facial or mid-lingual and distal area of each tooth.

\section{CALIBRATION OF SCORING}

Of considerable importance in any study is the ability to reproduce the method of scoring with a known minimum error. In a toothbrush study, control of the accuracy of the scoring criteria becomes increasingly important, especially with the small differences that may be present in plaque and gingivitis scores. ${ }^{1}$

An analysis of the reproducibility of the scoring method showed that the examiner's average deviation for plaque score was \pm 0.028 , for gingivitis \pm 0.072 , for calculus 0.0 , for periodontal scores \pm 0.024 , and for crevice depth \pm 0.086 .

\section{FORMATION OF GROUPS}

In forming comparable groups for this study initial plaque, gingivitis, periodontal disease, and crevice depth were scored on all subjects. A prophylaxis was given to all subjects. Scores for all categories were taken again 5-7 days after prophylaxis. Means and standard deviation were calculated for all initial and 5-7 day scores as patients were placed in groups until equivalent groups were formed. Subjects were not matched score for score, and groups cannot be considered as matched pairs for statistical evaluations. Thus, this study utilized groups matched for means and standard deviation rather than matched pairs.

An analysis of the means for Groups I and II before and after prophylaxis is given in Table 1. There were no significant statistical differences between the groups for plaque, gingivitis, periodontal disease index and crevice depth. In forming the groups, consideration also was given to age and sex so that the two groups would be comparable in this respect as well as with the other scores. Group I consisted of 39 individuals: 18 males and 21 females whose age range was from 22 years to 70 years with the mean age being 41.3 years. Group II consisted of 37 individuals: 17 males and 20 females whose age range was from 21 years to 73 years with the mean age being 45.5 years.

\section{TYPES OF BRUSHES}

Two types of brushes were used in this study. The high speed reciprocating action brush* has an amplitude of 3/16 inch and a speed of approximately 2,000 strokes per minute. It consists of a battery-powered handle, a charger unit, and a brush. The brush has four rows of nylon bristles $7 / 16$ inch long. There are seven tufts to each row and approximately 15 bristles to each tuft. The width of the bristle area is $3 / 4$ inch long and $3 / 8$ inch wide with the bristle diameter being 0.012 inch.

The Lactona No. 12 hand toothbrush* has a solid handle and two rows of six tufts containing hard natural bristles with a

\footnotetext{
*Supplied by the General Electric Company.
} 
straight cut design. This brush was chosen since it is one type recommended to patients at the University of Michigan in their oral hygiene program and since a natural brush is one of the more commonly used brushes.

\section{TOOTHBRUSHING INSTRUCTIONS}

At the beginning of the study and again at 60 days from the beginning of the study when the brushes were switched, all patients were instructed in the desired method of use for each brush. The patient then demonstrated his ability to follow this technic.

Patients instructed in the roll method of brushing were told to place the sides of the bristles on the attached gingiva with the bristles parallel to the long axis of the teeth. The bristles should be pressed momentarily against the attached and marginal gingiva causing a blanching of the tissue. The brush was then moved occlusalward over the gingiva and the tooth by rolling the wrist. Following this method, the bristles sweep down on the maxillary teeth and up on the mandibular teeth. This rolling motion was to be carried out several times in each area of the mouth until the entire mouth, buccal and lingual, was systematically covered.
Instructions with the automatic brush were also given. The patient was told to place the brush at right angles to the long axis of the teeth at the level of the marginal gingiva. The brush was then started and moved a few millimeters vertically covering the attached gingiva and the facial and lingual or palatal surfaces of the teeth. At the same time it was moved horizontally until the entire arch and mouth was systematically brushed. In the maxillary anterior palatal area and the mandibular anterior lingual area, the patients were instructed to hold the brush parallel with the long axis of the teeth so that the movement of the brush head was in a vertical manner rather than in a horizontal manner. This placement was thought to provide greater access due to the constriction caused by the curvature of the arch in the anterior area of the mouth.

Patients were allowed to continue to use any accessory aids they normally used in their oral hygiene program but were told to use these aids with both the standard design and the electric toothbrush. No attempt was made to control the number of times the patient brushed his teeth at any time in the study with either brush.

$\mathrm{T}_{\mathrm{ABLE}} 1$

Basis for Grouping Patients Before Prophylaxis

\begin{tabular}{|c|c|c|c|c|c|c|c|}
\hline \multirow[b]{2}{*}{ Group } & \multirow{2}{*}{$\begin{array}{c}\text { Mean } \\
\text { Age }\end{array}$} & \multirow[b]{2}{*}{$M$} & \multirow[b]{2}{*}{$F$} & \multicolumn{4}{|c|}{ Mean Scores } \\
\hline & & & & Plaque & Gingivitis & Periodontal & Crevice Depth \\
\hline I & 41.3 & 18 & 21 & $\begin{array}{c}1.094 \\
\pm .027^{*}\end{array}$ & $\begin{array}{c}1.039 \\
\pm .044^{*}\end{array}$ & $\begin{array}{c}4.043 \\
\pm .090^{*}\end{array}$ & $\begin{array}{c}2.415 \\
\pm .066^{*}\end{array}$ \\
\hline II & 45.5 & 17 & 20 & $\begin{array}{c}1.096 \\
\pm .038^{*}\end{array}$ & $\begin{array}{c}1.052 \\
\pm .048^{*}\end{array}$ & $\begin{array}{c}4.099 \\
\pm .056^{*}\end{array}$ & $\begin{array}{c}2.410 \\
\pm .060^{*}\end{array}$ \\
\hline \multicolumn{8}{|c|}{ Five Days After Prophylaxis } \\
\hline & & & & \multicolumn{4}{|c|}{ Mean Scores } \\
\hline Group & Age & M & $F$ & Plaque & Gingivitis & Periodontal & Crevice Depth \\
\hline I & 41.3 & 18 & 21 & $\begin{array}{c}0.857 \\
\pm .040^{*}\end{array}$ & $\begin{array}{c}0.666 \\
\pm .044^{*}\end{array}$ & $\begin{array}{c}3.934 \\
\pm .093^{*}\end{array}$ & $\begin{array}{c}2.406 \\
\pm .058^{*}\end{array}$ \\
\hline II & 45.5 & 17 & 20 & $\begin{array}{c}0.874 \\
\pm .035^{*}\end{array}$ & $\begin{array}{c}0.648 \\
\pm .053^{*}\end{array}$ & $\begin{array}{c}4.101 \\
\pm .050^{*}\end{array}$ & $\begin{array}{c}2.367 \\
\pm .060^{*}\end{array}$ \\
\hline
\end{tabular}

*Standard Error. 


\section{CLINICAL PROCEDURES}

At the beginning of the study all patients were scored for initial scores in plaque, gingivitis, periodontal disease index, and crevice depth. A complete prophylaxis was given. At 5-7 days following the prophylaxis, scoring in all categories was again done. The removal of all dental plaque and calculus caused a significant reduction in the gingivitis score. However, periodontal disease scores or crevice depth were not significantly altered (Table 1 ). Using these scores, initial and 5-7 day scores, formation of groups for study was possible.

After the patients were assigned to groups, each patient in Group I was given two Lactona hard natural bristle toothbrushes and toothbrushing instructions. After the instructions, patients were requested to demonstrate their ability to perform the technic of brushing. Subjects also were instructed to use no brush except those provided and to alternate the brushes at each brushing. At the end of 30 days the old brushes were discarded and each of the patients was given two new Lactona brushes and told to follow the same brushing technic for the second 30 day period as they had followed during the first 30 days.

Patients assigned initially to Group II were given an automatic toothbrush with three interchangeable nylon bristle heads. They also were instructed in a method of use for the automatic brush and then demonstrated this method. They also were told to use only the automatic brush and to alternate the brushes. Similarly at 30 days this group was furnished with three new replacement brushes and told to continue in a similar manner for the second 30 days.

After 60 days' use of the brushes, both groups were scored for all categories: calculus, plaque, gingivitis, periodontal scores, and crevice depth. Each patient then received a complete prophylaxis. The automatic toothbrushes were collected from Group II and stored; the hand brushes used by Group I were discarded. Group I changed to the automatic brush, and Group II was given the Lactona hard natural bristle hand brushes. New instructions were given to all participants in the desired method of brushing. New toothbrushes or new replaceable heads were supplied to both groups at 30 days from the time the change of brushes occurred. At 60 days from the time the brushes were switched, or at 120 days from the beginning of the study, the final scoring was done.

\section{STATISTICAL ANALYSIS OF DATA}

Scores from this study were statistically evaluated to analyze between group and within group differences. The means of the plaque scores of the two groups were used as an indication of the effectiveness of the brushes in preventing or removing dental plaque from the teeth. The means of the gingivitis and periodontal scores were used as an indication of the effect of the brushes on the periodontium. The means of the calculus scores indicated the effectiveness of the brushes in preventing or altering the formation of calculus. Means of the measurements of the gingival crevice and periodontal pocket depths note the effectiveness of the brushes at altering gingival crevice or pocket depth. A comparison of the mean calculus, plaque, gingivitis, and periodontal scores between Group I and Group II would indicate the relative effectiveness of the automatic brush and the hand brush. The " $t$ " test was used to analyze the differences within and between the groups.

\section{RESULTS}

The statistical analysis of the means of the scores for the groups showed there was no statistically significant difference at the 0.01 level of confidence between the means for Group I and Group II for plaque, gingivitis, calculus, periodontal disease index, and the depth of the gingival crevice at any time during the investigation (Table 2).

In Group I there was no statistically significant difference at the 0.01 level of confidence within the group at any time 


\section{RaINEY AND Ash}

TABLE 2

Comparison Between Group I and Group II at 60 Days and 120 Days (60 Days on Each Brush)

\begin{tabular}{|c|c|c|c|c|c|c|c|}
\hline \multirow[b]{2}{*}{ Group } & \multirow{2}{*}{$\begin{array}{c}\text { Toothbrush } \\
\text { Utilized }\end{array}$} & \multirow{2}{*}{$\begin{array}{l}\text { Time } \\
\text { in Days }\end{array}$} & \multicolumn{5}{|c|}{ Mean Scores } \\
\hline & & & Plaque & Gingivitis & Calculus & Periodontal & Crevice Depth \\
\hline $\mathrm{I}$ & Hand brush & 60 & $\begin{array}{l}1.097 \\
\pm .021 *\end{array}$ & $\begin{array}{l}0.896 \\
\pm .033^{*}\end{array}$ & $\begin{array}{l}0.108 \\
\pm .014^{*}\end{array}$ & $\begin{array}{c}4.101 \\
\pm .079^{*}\end{array}$ & $\begin{array}{c}2.404 \\
\pm .051^{*}\end{array}$ \\
\hline II & Electric & 60 & $\begin{array}{c}1.036 \\
\pm .024^{*}\end{array}$ & $\begin{array}{c}0.778 \\
\pm .031^{*}\end{array}$ & $\begin{array}{c}0.112 \\
\pm .018^{*}\end{array}$ & $\begin{array}{c}4.049 \\
\pm .050^{*}\end{array}$ & $\begin{array}{c}2.334 \\
\pm .049^{*}\end{array}$ \\
\hline \multicolumn{8}{|c|}{ Prophylaxis Rendered and Toothbrushes Switched } \\
\hline & Tootbbrush & Time & \multicolumn{5}{|c|}{ Mean Scores } \\
\hline Group & Utilized & in Days & Plaque & Gingivitis & Calculus & Periodontal & Crevice Depth \\
\hline I & Electric & $\begin{array}{c}60 \\
\left(120^{* *}\right)\end{array}$ & $\begin{array}{l}1.047 \\
\pm .014^{*}\end{array}$ & $\begin{array}{l}0.718 \\
\pm .047^{*}\end{array}$ & $\begin{array}{l}0.095 \\
\pm .012^{*}\end{array}$ & $\begin{array}{l}4.045 \\
\pm .085^{*}\end{array}$ & $\begin{array}{c}2.342 \\
\pm .058^{*}\end{array}$ \\
\hline II & Hand brush & $\begin{array}{c}60 \\
\left(120^{* *}\right)\end{array}$ & $\begin{array}{c}1.015 \\
\pm .029^{*}\end{array}$ & $\begin{array}{l}0.695 \\
\pm .042^{*}\end{array}$ & $\begin{array}{l}0.075 \\
\pm .010^{*}\end{array}$ & $\begin{array}{c}4.020 \\
\pm .050^{*}\end{array}$ & $\begin{array}{c}2.157 \\
\pm .042^{*}\end{array}$ \\
\hline
\end{tabular}

*Standard Error.

**Time From Beginning of Study.

period for plaque, calculus, periodontal disease index, or crevice depth. There was a statistically significant reduction in gingivitis in Group I during the first 60 day period of the study while using the manual brush and in the second 60 day period while using the automatic brush.

In Group II there was no statistically significant difference at the 0.01 level of confidence within the group at any time period for plaque, calculus, or periodontal disease index. There was a significant reduction at the 0.01 level of confidence in gingivitis during the first 60 day period while using the automatic brush, but not during the second 60 day period while using the manual brush. In Group II there was no significant difference in the mean for crevice depth during the first 60 days of the study. However, during the second 60 days while using the manual brush there was a significant reduction in crevice depth for this group.

\section{DISCUSSION}

The reduction in gingivitis occurring in Group I and in Group II during the first 60 day period can be attributed to several factors, the most important probably being related to receiving a prophylaxis at the beginning of this period. Another factor favorable for both groups may have been the enthusiasm of being included in a toothbrush study. Patients in Group I, who started on the hand brush, were told they would be given an electric brush at the end of the first 60 days. This could have generated some enthusiasm for carrying out the recommended oral hygiene procedures during the first 60 day period. Patients in Group II who started on the electric brush must have been affected in their cleaning procedures by the novelty effect of a new electric brush. This effect has not been adequately evaluated; however, it is felt to play an important part in brush effectiveness in a study of this nature.

In the second 60 day period there was a significant reduction in gingivitis at the 0.01 level of confidence in Group I who used the electric brush but not in Group II who used the manual brush. This reduction also may be explained by several factors. Enthusiasm for the study may have played a part here, but in favor of the group using the electric brush. Group II who had used the hand brush during the second 60 day period may have found the change to this 
brush to be somewhat of an anticlimax or likened to a return to the old way of brushing, and therefore a relaxation in carrying out the recommended oral hygiene procedures resulted. Group I patients, who received an electric brush, continued to be enthused about the study and the novelty of having an electric brush. These differences could have affected the mean results in the final analysis of the figures.

In addition to this, it is felt that the significant difference noted could have been due to chance and/or the scoring error of the investigator. The mean reduction in gingivitis was 0.178 units for the group using the electric brush. This reduction approximates the calculated scoring error for scoring gingivitis which was found to be \pm 0.072 .

Statistical evaluation of alteration of gingival crevice depth shows there was no statistically significant reduction in either group during the first 60 days of the study. However, during the second 60 days, there was a statistically significant reduction at the 0.01 level of confidence in the group using the manual toothbrush, while there was no significant reduction in crevice depth in the group using the electric brush during the second 60 days. This reduction could also be due to chance and/or to the errors in scoring. The mean reduction in crevice depth in the group using the manual brush was 0.177 millimeters. This reduction also approximates the scoring error for measurement of crevice depth which was \pm 0.086 .

Two additional facts suggest that the differences in gingivitis and crevice depth were due to chance and/or experimental error: (1) there were no significant differences in plaque, calculus, and periodontal disease indices during the first and second 60 day periods, and (2) there were no differences in reduction of gingivitis or crevice depth during the first 60 days of the study. Furthermore, if such small reductions are real, they are of questionable biologic significance.
Finally, acceptance of the differences as real would mean that one brush is better for reduction of gingivitis than the other, and one brush is better than the other for reduction of crevice depth. Because of the close relationship of crevice depth and gingivitis, one might expect a closer correlation than suggested by the differences in reduction of gingivitis and crevice depth observed in the second 60 day period of this study.

\section{SUMMARY}

A comparison of the effects of a short stroke reciprocating action automatic toothbrush and a hard natural bristle manually operated toothbrush (Lactona) was made on 76 patients for a period of 120 days. A study was made of dental plaque, gingivitis, periodontal disease indices, calculus, and the depth of the gingival crevice. Two comparable groups, one consisting of 39 individuals and another of 37 individuals, were formed initially by determination of plaque, gingivitis, periodontal disease index, and gingival crevice depth. One group started on the automatic toothbrush and the other group started on the manually operated toothbrush (Lactona). Plaque, gingivitis, periodontal and calculus scores, and gingival crevice depths were obtained at 60 days and 120 days. The type of brush used by each group was switched at 60 days. A statistical evaluation was made for between group scores at 0, 60, and 120 days, and for within group scores for 0-60 and 60-120 days.

\section{CONCLUSION}

Within the limits of the study the following conclusions are made: the automatic toothbrush and the hard natural bristle toothbrush are (1) equally effective in the prevention of plaque and calculus, and (2) have an equal effect on gingivitis, periodontal disease index, and the depth of the gingival crevice.

\section{BIBLIOGRAPHY}

1. Ash, Major M., Jr. A review of the problems and results of studies on manual and power toothbrushes. J. Periodont., 35:202-13, May-June 1964. 
2. Berman, C. L., Hosiosky, Ellen N., Kutscher, A. H., and Kelly, Audrey. Observations of the effects of an electric toothbrush. J. Periodont., 33:195-8, Apr. 1962.

3. Birch, F. H., and Mumford, J. M. Electric toothbrushing. Dent. Pract. and Dent. Record, 13: 182-6, Jan. 1963.

4. Chilton, N. W., and El-Kashlan, Khalil. A modified analysis of variance in a clinical toothbrushing experiment. J. Dent. Res., 41:84-95, Jan.-Feb. 1962.

5. Chilton, N. W., DeDio, A., and Rothner, J. $T$. Comparison of the clinical effectiveness of an electric and a standard toothbrush in normal individuals. Am. Dent. A. J., 64:777-82, June 1962.

6. Cross, W. G., Forrest, J. O., and Wade, A. B. A comparative study of tooth cleansing using conventional and electrically operated toothbrushes. Brit. Dent. J., 113:19-22, July 1962.

7. Derbyshire, J. C., and Mankodi, S. N. Gingival keratinization with hand and electric toothbrushes: a cytological comparison. Am. Dent. A. J., 68:255-9, Feb. 1964.

8. Elliot, J. Roy. A comparison of the effectiveness of a standard and an electric toothbrush. J. Periodont. 34:75-9, July 1963.

9. Green, A., Rosenstein, S. N., Parks, Allen, and Kutscher, A. H. The electric toothbrush as an adjunct in maintaining oral hygiene in handicapped patients. J. Dent. for Children, 29:169-71, 3rd Quarter, 1962.

10. Hoover, D. R., and Robinson, H. B. G. Effect of automatic toothbrushing on gingivitis. Am. Dent. A. J., 65:361-7, Sept. 1962.

11. Iwersen, A. E., and Werking, D. H. Hand and automatic toothbrushes: effectiveness in inhibiting brown pellicle. Am. Dent. A. J., 68:178-81, Feb. 1964.

12. Jamison, H. C. Prevalence and severity of periodontal disease in a sample of a population. University of Michigan, School of Public Health, 1960. XI + 153 p. typed thesis.
13. Kapur, Krishan, and Shklar, Gerald. Effects of a power device for oral physiotherapy on the mucosa of the edentulous ridge. J. Pros. Dent., 12: 762-9, July-Aug. 1962.

14. Kelner, M. Comparative analysis of the effects of automatic and conventional toothbrushing in mental retardates. Penn. Dent. J., 30:102-8, Apr. 1963.

15. Lefkowitz, William, and Robinson, H. B. G. Effectiveness of automatic and hand brushes in removing dental plaque and debris. Am. Dent. A. J., 65:351-61, Sept. 1962.

16. Parfitt, Gilbert J. Cleansing the subgingival space. J. Periodont., 34:133-9, March 1963.

17. Quigley, G. A., and Hein, H. W. Comparative cleansing efficiency of manual and power brushing. Am. Dent. A. J., 65:26-9, July 1962.

18. Ramfjord, Sigurd. Indices for prevalence and incidence of periodontal disease. J. Periodont., 30 : 51-9, Jan. 1959.

19. Sanders, W. E., and Robinson, H. B. G. Effect of toothbrushing on deposition of calculus. J. Periodont., 33:386-90, Oct. 1962.

20. Savastano, Gennaro. Evaluation of an automatic action toothbrush in children. Dent. Digest, 68:19-21, Jan. 1962.

21. Shick, R. A., and Ash, M. M., Jr. Evaluation of the vertical method of toothbrushing. J. Periodont., 32:346-53, Oct. 1961.

22. Smith, W. A., and Ash, M. M., Jr. A clinical evaluation of an electric toothbrush. J. Periodont., 35:127-36, Mar.-Apr. 1964.

23. Sopakar, P. M., and Quigley, G. A. Power versus hand brushing: effect on gingivitis. Am. Dent. A. J., 68:182-7, Feb. 1964.

24. Stahl, S. S., Wachtel, N., DeCastro, C., and Pelletier, G. The effect of toothbrushing on the keratinization of the gingiva. J. Periodont., 24:20-1, Jan. 1953.

25. Toto, P. D., and Farchione. A. Clinical evaluation of an electrically powered toothbrush in home periodontal therapy. J. Periodont., 37:249-54, July 1961.

\title{
Abstract....
}

\section{A PHOTOELECTRIC METHOD FOR RECORDING JAW DISORDERS}

\author{
Gillings, B. R. D. and Graham, C. H.
}

J. Den. Res. 43:305, 1964

A method employing fixed light sources and paired photoelectric cells is described for recording jaw movements in the vertical, lateral, and anteroposterior planes. Photoelectric cell outputs resulting from the positional changes of light sources during mandibular excursions are balanced and the signal fed into a push-pull D.C. amplifier which drives the pen of a rectilinear heat-writing recorder. This system has the obvious advantage of no mechanical linkage between jaw and recording device thus allowing unhindered movements of the mandible. 